\title{
Implantation of total artificial heart in a 10-year-old after support with a temporary perventricular assist device
}

\author{
Mohamad Alaeddine, MD, ${ }^{\mathrm{a}}$ Michelle Ploutz, MD, ${ }^{\mathrm{b}}$ Francisco A. Arabía, MD, MBA, ${ }^{\mathrm{c}}$ and \\ Daniel A. Velez, MD, ${ }^{\mathrm{d}}$ Phoenix, Ariz
}

\footnotetext{
From the ${ }^{\mathrm{a}}$ Division of Cardiothoracic Surgery, ${ }^{\mathrm{b}}$ Mechanical Circulatory Support, Heart Center, and ${ }^{\mathrm{d}}$ Division of Cardiothoracic Surgery, Phoenix Children's Hospital, Phoenix, Ariz; and ' Advanced Heart Programs, Banner University, Phoenix, Ariz.

No financial support was used for the report.

Disclosures: Dr Arabia receives personal fees as a SynCardia systems instructor/trainer. Dr Velez serves on the Admedus advisory board for the use and design of bovine pericardial patches. All other authors have nothing to disclose with regard to commercial support.

Received for publication May 24, 2019; revisions received July 18, 2019; accepted for publication July 22, 2019; available ahead of print Sept 26, 2019

Address for reprints: Daniel A. Velez, MD, Division of Cardiothoracic Surgery, Phoenix Children's Hospital, 1919 E Thomas Rd, Main Tower, Phoenix, AZ 85016 (E-mail: dvelez@phoenixchildrens.com).

J Thorac Cardiovasc Surg 2020;159:e227-9

$0022-5223 / \$ 36.00$

Copyright (C) 2019 by The American Association for Thoracic Surgery

https://doi.org/10.1016/j.jtcvs.2019.07.101
}

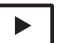

Video clip is available online.

The use of the SynCardia Temporary Total Artificial Heart (TAH-t; SynCardia Systems, LLC, Tucson, Ariz) within the pediatric population has been limited mostly due to concerns regarding device fit. Recently, SynCardia has developed the 50-cc TAH-t, which is currently undergoing a Food and Drug Administration clinical trial. The most extensive pediatric experience to date was published by Villa and colleagues ${ }^{1}$ in 2017 . They reported a total of

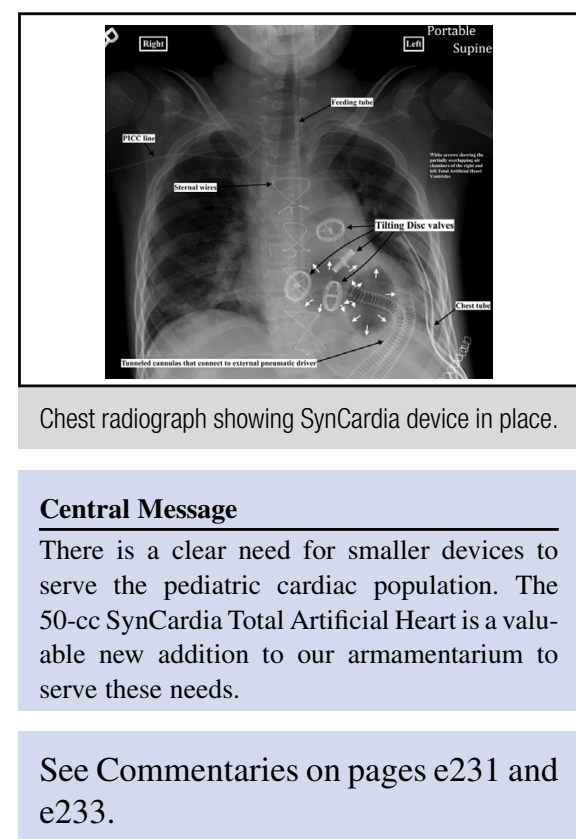

43 patients younger than 21 years of age who received a TAH-t between 2005 and 2015. Pediatric patients overall had similar survivals to adults, with $70 \%$ of patients alive on device support or receiving transplants at 30 days. With a smaller footprint, the new device can be considered in smaller patients, potentially expanding the use of the

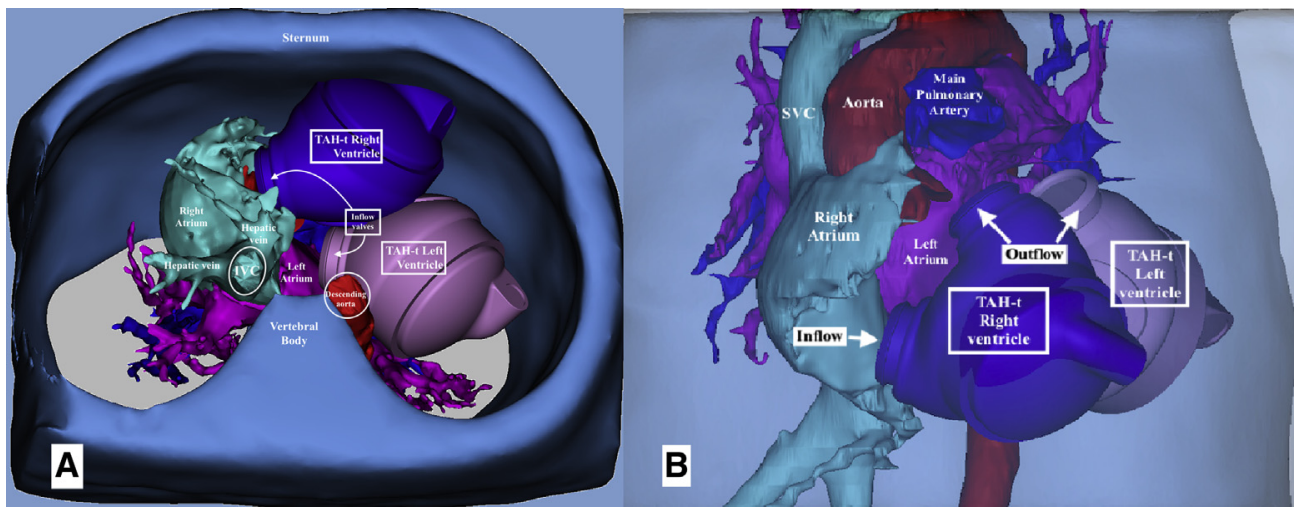

FIGURE 1. Axial cephalad view (A) and frontal coronal view (B) of the virtual fit study of the 50-cc SynCardia temporary Total Artificial Heart device (TAH- $t$; SynCardia Systems, LLC, Tucson, Ariz). Three-dimensional reconstructed magnetic resonance imaging of the patient was used. The cardiac mass was removed, and the device was placed inside the mediastinal cavity as was surgically intended. This study provides visual assessment of the device fit. The virtual fit study is most helpful when the T10 is at the minimum required $10 \mathrm{~cm}$. T10 is the distance in centimeters from the anterior surface of the vertebral body to the posterior sternal plate at the level of 10 th thoracic vertebra. $I V C$, Inferior vena cava; $S V C$, superior vena cava. 


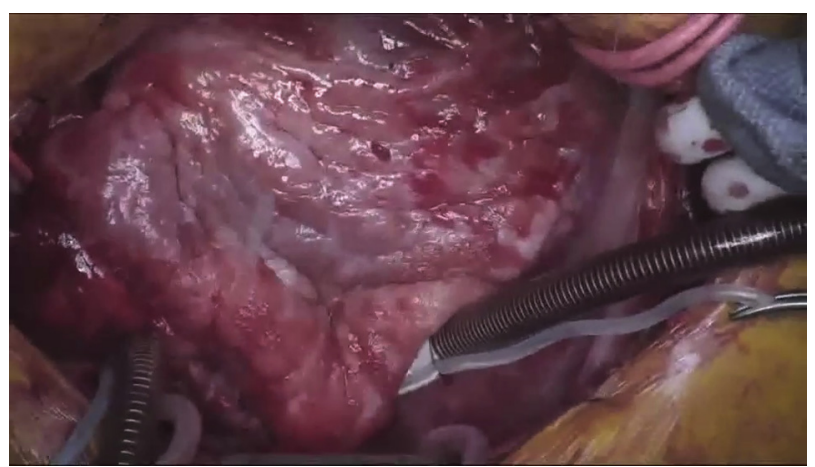

VIDEO 1. Video of the actual surgery captured from the overhead camera. Video available at: https://www.jtcvs.org/article/S0022-5223(19)31660-5/ fulltext.

TAH-t within the pediatric population. We report the successful use of a 50-cc SynCardia TAH-t as a bridge to transplant in a 10-year-old child (weight, $48 \mathrm{~kg}$; body surface area, $1.42 \mathrm{~m}^{2}$ ) with idiopathic dilated cardiomyopathy. Our patient did well, with no significant postoperative or device complications. This report represents the youngest patient supported by a TAH in the United States.

\section{CLINICAL SUMMARY}

A previously healthy 10 -year-old male child had acute cardiopulmonary arrest occur while he was at home. $\mathrm{He}$ was defibrillated and stabilized in the field by emergency medical services and was transported to our institution supported by an amiodarone infusion. Diagnostic workup included a transthoracic echocardiogram and a cardiac

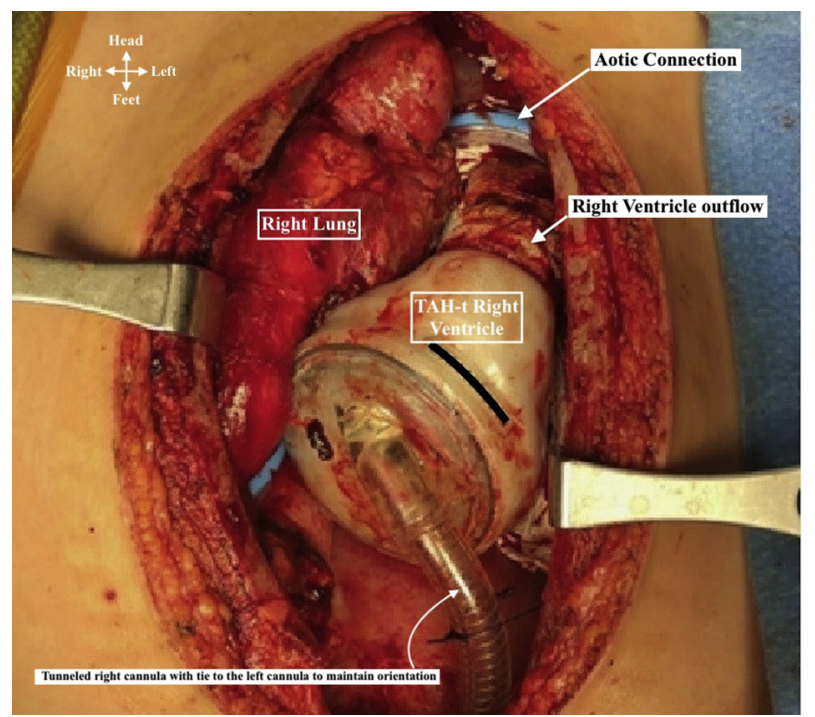

FIGURE 2. Intraoperative picture showing the temporary Total Artificial Heart (TAH-t; SynCardia Systems, LLC, Tucson, Ariz) right ventricle inside the mediastinum. Not showing is the TAH-t left ventricle, which is sitting leftward and posterior to it. The picture shows the appropriate fit with room for closure of the sternum.

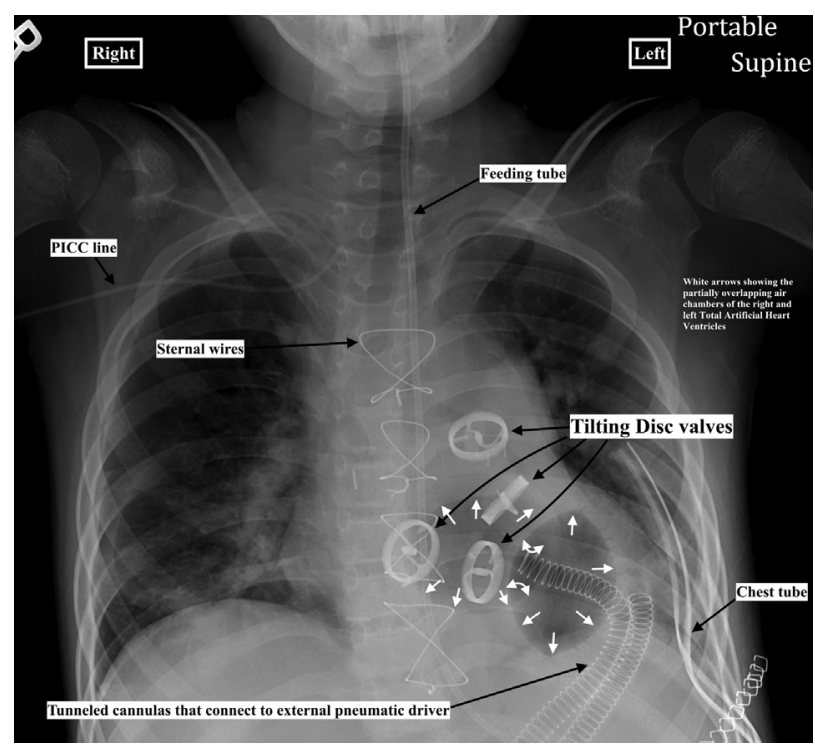

FIGURE 3. Chest radiograph showing SynCardia temporary Total Artificial Heart device (TAH-t; SynCardia Systems, LLC, Tucson, Ariz). PICC, Peripherally inserted central catheter.

magnetic resonance imaging scan, which revealed a severely dilated left ventricle (end-diastolic volume, $303 \mathrm{~mL} / \mathrm{m}^{2}$ ) with severely diminished function (ejection fraction, $13 \%$ ). A large basilar to apical inferior to inferolateral wall aneurysm was present, with evidence of subendocardial fibrosis. There was no significant noncompaction. Cardiac catheterization showed normal coronary arteries and normal right and left heart pressures, including a left ventricular end-diastolic pressure of $8 \mathrm{~mm} \mathrm{Hg}$ and a pulmonary vascular resistance of 1.76 indexed Wood units. He was extubated 5 days after admission, but refractory ventricular tachyarrhythmia developed later, requiring multiple rounds of cardiopulmonary resuscitation and cardioversion. Given the worsening ventricular dysrhythmias, the patient was treated with high-dose antiarrhythmics, sedated, and paralyzed. Unfortunately, with these interventions, significant bradycardia developed, with evidence of compromised cardiac output.

We elected to proceed with temporary mechanical support as a means to stabilize the patient before more durable mechanical support. We elected to use a $29 \mathrm{~F}$ Protek Duo cannula (LivaNova PLC, London, UK), inserted transapically, with a paracorporeal continuous-flow left ventricular assist device. After implantation, the patient was extubated and tolerated enteral nutrition with normal end-organ function while awaiting surgical planning for durable left ventricular assist device support.

The SynCardia TAH-t was selected for durable support to eliminate the effects of malignant ventricular arrhythmias and concern about tissue integrity around the left 
ventricular aneurysm. ${ }^{2}$ On the basis of the virtual fit study performed on the patient's previously obtained cardiac magnetic resonance imaging scan (Figure 1), we selected the 50-cc device as a bridge to transplant (Video 1).

The patient returned to the intensive care unit with an open chest (Figure 2). The patient was weaned from vasopressors and returned to the operating room for sternal closure the next morning. Anticoagulation with bivalirudin was started on postoperative day (POD) 4 and was transitioned to warfarin sodium on POD 21. Aspirin was started on POD 6. The patient was ambulating by POD 7 (Figure 3). On POD 21 he was switched to freedom drive and started attending in-house school.

The patient was on SynCardia TAH-t support for 69 days before transplantation without significant complications. His posttransplant course was uncomplicated, and the patient was discharged home 9 days after his heart transplant. He continues to do well and is progressing as expected.

\section{DISCUSSION}

The SynCardia TAH-t was ideal for this patient, because it allowed us to avoid any potential complications from ventricular arrhythmias. The virtual implantation fit study was extremely helpful in determining the appropriate device size. Although initially, we had considered the 70-cc device on the basis of the patient's body surface area $\left(1.42 \mathrm{~m}^{2}\right)$ and $\mathrm{T} 10$ measurement $(10 \mathrm{~cm})$, the virtual fit clearly demonstrated that the 50-cc device would be a better option.

We elected to use temporary mechanical support to allow patient stabilization and optimization of end-organ function before implantation of the SynCardia TAH-t. The Berlin EXCOR (Berlin Heart GmbH, Berlin, Germany) trial demonstrated that children with evidence of renal or hepatic dysfunction had a 4- to 7-fold increase in mortality. ${ }^{3}$ Although our patient required significant inotropic and antiarrhythmic support, he had no significant end-organ dysfunction at device implantation, which likely helped to mitigate any postoperative complications and allowed a smooth recovery.

The SynCardia TAH-t is a viable option as a bridge to transplant in appropriately selected pediatric patients. With the advent of the 50-cc device, this support can now be extended to a younger patient population.

\section{References}

1. Morales DLS, Lorts A, Rizwan R, Zafar F, Arabia FA, Villa CR. Worldwide experience with the Syncardia total artificial heart in the pediatric population. ASAIO J. 2017;63:518-9.

2. Arabía FA, Cantor RS, Koehl DA, Kasirajan V, Gregoric I, Moriguchi JD, et al. Interagency registry for mechanically assisted circulatory support report on the total artificial heart. J Heart Lung Transplant. 2018;37:1304-12.

3. Almond CS, Morales DL, Blackston EH, Turrentine MW, Imamura M Massicotte MP, et al. Berlin heart EXCOR pediatric ventricular assist device for bridge to heart transplantation in US children. Circulation. 2013;127: 1702-11. 